\title{
THE STEDEGENHET OF NORDIC STS
}

\author{
by Henrik Karlstrøm \& Terje Finstad
}

The increasing formalization of STS research networks in the Nordic countries prompts a discussion of how research and academic work in the region is constituted - what makes something 'Nordic' STS as opposed to just 'regular' STS? Similarly, the degree to which international STS theories can be translated into a Nordic institutional context is a matter of importance for assessing the type of work that is being done by Nordic STS researchers. The article provides an overview of STS-related institutions and activities in the Nordic countries, and discusses the diffusion and diffraction of STS theory across national and institutional barriers. 


\section{Introduction}

In April 2013, the first Nordic conference specifically oriented towards science and technology studies (STS) was arranged in Hell, Norway. The idea of the conference was to have a meeting place for people working in STS or on STS-related topics, a platform for discussion that was amenable to the growing community of STS in the Nordic countries. With more than 130 participants - a sizeable share of the active STS community in the Nordic countries it attests to the strengthening position of the field of STS, a field which may not be as institutionally strong anywhere else than in just this region. With room made for national meetings of the constituent STS networks in the various countries, the conference seemed to confirm that there was need for a further integration of STS research between the Nordic communities, as well as a need for a place where young scholars could present their projects and research and where established scholars could convene to network and plan projects, all within a setting which was not overwhelmingly large.

At the conference, a panel debate was arranged to discuss if such a thing as 'Nordic STS' could be said to exist, and what it might even be. The four panel participants, one from each Nordic country present except Iceland, were reluctant to define what Nordic STS could be or constitute. At most, it might consist of a set of research priorities, tied to the specific historical and political context of the Nordic countries - for example, the largely public system for care for the elderly has led to investigations into so-called 'welfare technologies' in Denmark. The sentiment seemed to be that it makes little sense to try and distinguish STS in these countries from what is going on in other places, since STS is in its nature a global and cross-national field of inquiry. The theories and to some extent the empirical investigations travel between countries and look more or less the same everywhere. At most, Nordic STS can be summed up as a sort of communality grounded in shared research interests and a mostly shared language base. This view is echoed by Sheila Jasanoff, who in a talk given at the University of Oslo in September 2012 entitled "A field in spite of itself" discussed various ways of conceptualizing cross-disciplinarity.' In contrast to the more standard way of looking at disciplines - as territories separated by clearly demarcated borders closely guarded by jealous gatekeepers - it might be better to see them as islands in a large sea, with the uncharted territories between the islands representing the space for interdisciplinary explorations. In her version of the story, STS researchers can be likened to seafarers, charting the waters between established disciplines and establishing new connections for the exchange of knowledge.

What we wish to do here is to investigate this claim a little closer. Not because we think the metaphor of intrepid disciplinary
Argonauts is necessarily wrong (although it is perhaps more of an ideal to strive towards than an accurate description of today's STS field), but because it opens up for some interesting avenues of investigation, of which we will mention two. Firstly, there is reason to ask whether STS as a field can be said to be uniform, and even whether this is something to strive for. One argument against this could be based on STS-theory. Many of the STS-theories utilized across the world have significant things in common and make it possible for STS-scholars to understand each other even if they are studying vastly different contexts. As many of these theories say, however, there can be no doubt that travelling theories and perspectives have to be appropriated, integrated and domesticated into local context. Secondly, the consolidation of a Nordic STS community is in itself a reflection of a specific institutional context tied to a set of priorities dictated by the needs of the funders of social research in the Nordic countries - mostly the nation-states of Denmark, Finland, Norway and Sweden - which again ties into notions of shared history and an attempt to stake out a third course between the two dominating post-WWII political blocks.

This consolidation, most recently demonstrated through the establishing of a new pan-Nordic network of STS research and a biannual conference of research done by Nordic scholars, also marks the demand for a platform for the further dissemination of this work. This is where a journal for Nordic STS research can find its raison d'etre, both as a home for empirical investigations that might not be deemed of general enough importance for the larger STS publishing channels and as a window in from outside showcasing the academic work done in the region.

In this article, we want to point to the aspects of STS work done in the Nordic region that could justify using a term that encompasses five countries and hence five different institutional settings. We believe that many of the concepts that have been developed within the STS discipline since its inception, such as the notion of translation and intermediaries (Callon, 1986), the existence of parallel types of expertise (Collins \& Evans, 2008) and coproduction (Jasanoff, 2004) to name just a few, are exactly the approaches that allow us to analyze critically the movement of these very theories. In the following sections, we will discuss how both theory and empirical work can be understood as arising within specific institutional contexts. Then we see how such an understanding can shed light on developments by examining the types of STS research done in Nordic institutions. Finally, we point to ways this work can be made relevant to the larger, global STS context, both by providing interesting empirical examples and by highlighting the flexibility and adaptability that current STS thought allows for. 


\section{The shaping of theory}

The question of theory in relation to a place-specific instance of STS can be seen from two vistas, roughly corresponding to the difference between theoretical and empirical investigations. On the one hand, there is the question of the form of theory that can be adopted or developed in any given context, meaning the ways in which the theory is enabled or constrained by external factors. To give an example: to what degree do the politics of research funding - the priorities of the funders - dictate the types of scholarly inquiry that are considered legitimate answers to specific societal needs? And in what way does the historical shaping of political institutions, for example an expansive welfare state or the specifics of a perhaps surprisingly successful post-war class compromise, give rise to specific theoretical perspectives that arouses the interest of researchers? We are thinking here of theories employed by STS scholars working in Nordic countries and adapted to Nordic empirical realities: what perspectives have been taken up, and how? On the other hand, there are the various topics embedded in the empirical questions that Nordic scholars have focused on. Given that the Nordic setting for politics, scientific focus, technological development and many other fields is empirically different from the European continental or American ones, there are other types of factual investigations that can be made. Here, we will discuss how differences in institutional organization have given Nordic STS research a slightly different focus from many of its continental or Anglo-Saxon peers.

Before that, some words about the word 'Nordic'. It is potentialIy a problematic one. It presupposes a shared affinity between people working in different institutional contexts and languages, solely based on a politically/culturally constructed idea of similarity. To insist that there is something more than that, a sort of quintessential 'Nordicness' which influences all Nordic STS scholars and somehow sets us apart from others, carries with it certain questionable implications, not least what this entails for the communication between regions and the movement of scholars across institutional borders. However, it is a fact that there is a large degree of cooperation within the Nordic region, with both strong historical precedence and political basis. To the degree that we are only dealing with professional cooperation and a tendency to talk to each other about what we are doing, we do not see a big problem in talking about Nordic STS as a sort of entity in itself.

One reason for choosing to stay with the notion of Nordic STS, would be to discuss what happens as theory travels into our regional and national contexts. Even though they are often treated as such, theoretical concepts do not enter the world from a vacuum, but rather arise out of a particular time, place and institutional setting. So, concepts used by Nordic STS-scholars can be expected to be shaped by the particular institutional context in the Nordic countries in one way or another. This might be a somewhat banal statement, but as Nordic STS seems to be in a process of increased institutionalization, it's important to remain sensitive to how contexts shape our readings and uses of theory.
We can take Jasanoff's work on the American justice system as an example (Jasanoff, 1995), and compare it with Bruno Latour's on the French (Latour, 2010). Jasanoff studies the making of law through the lens of scientific evidence and the appeals of lawyers and judges to scientific facts in order to produce 'truth', all with clear political implications. Already on the very first page Jasanoff refers to the 'distinctive flavor' of the tendency in American politics to resolve social conflicts by means of the legal system. Latour deals with the way legal authority in the French system relies on a complex mesh of historical precedence embedded in the very make-up of its supreme court, "entirely fabricated, over two centuries, by the judges themselves", as he writes in the preface. It is not that the American system could not have been analysed using Latour's reference points or vice versa, but rather that it would look different due to the different context in which French and American law have been produced in and produces. The legal system of the Declaration of Independence does not operate in the same way as that of Napoleon and the Conseil d'Etat.

Another, similar example of how differing contexts can play into our theorization in the field of STS can be drawn from the fact that Nordic countries are often portrayed as the perfect example of how a sustainable modern market economy can be produced and maintained - the so-called Nordic Model (Andersen et al., 2007; Christiansen, 2006) which seeks to limit the purview of markets in favour of an extensive social security net and has been held up as an alternative for reform in countries like the United States (Jantti et al., 2006). However, it would be false to pretend that the market is the same thing in the US, France and the state-dominated economies of the Nordic countries. When the state is a major player in most spheres of the economy - owner of some of the largest companies in most sectors, partner in annual wage negotiations vis-à-vis the private sector, provider of health care, arbiter of gender relations, to name a few - could this not mean that the analysis of the economy, labour relations, consumer patterns, must look different too?

Bruno Latour once wrote "Give me a laboratory and I will raise the world" (Latour, 1983). This was during the height of laboratory studies, before STSers started following lawyers, bureaucrats and politicians through society. However, STS has shown us how the specific meetings between sectors transform the world, and our theories about the world, in unexpected ways. This insight should of course be brought into a discussion of meetings between different flavours of STS - reflexivity is, after all, part of the DNA of the history of STS (Wynne, 2007). Could it not be that the development, introduction and domestication of central STS theories are reliant on the institutional arrangements of the contexts where these theories were produced, and that this reliance can in turn end up reflecting very specific notions of how society or politics should work, and hence, how research is done? Looking at exactly how a field is institutionally composed and re-composed could also reveal something about these notions. 


\section{The world we study}

In his history of the rise of STS in the UK, John Law (2008) traces the origins of the field to 1960 s sociologists with a special interest in technology, noting that the field of science studies branched off from mainstream sociology during the 1970s, taking up impulses from anthropology, geography, history of science and philosophy of science. In his telling, STS is a happy amalgam of other disciplines which seems to be a way forward for the social sciences. He also stresses the strength of 'arguing through case studies', which can be seen as an antidote against sweeping generalisations. The importance of case studies is also recognized by Peter Dear and Sheila Jasanoff in an essay discussing the relation between STS and the history of science. Here, they claim that STS is more an object centered field of study than a discipline in the narrow sense (Dear \& Jasanoff, 2010), meaning it consists more of a set of perspectives that can be mobilised in the analysis of a given phenomenon, for example through metaphors of networks, controversies or materiality, than a prescribed sequence of steps to follow. This is a reasoning common for other interdisciplinary fields such as visual culture studies, social geography or gender studies as well, all of which share a certain affinity with STS.

The distinction between a field and discipline can be useful for thinking about the meanings and implications of the term 'Nordic STS'. If STS is an interdisciplinary, object (or case) centered field, then the objects approached must be firmly placed in context. Thus, while the objects of STS might very well be global or universal, they are also inherently local. If cars are shaped by its cultural, political and economic environments, then there is all the reason to insist on that the history of the car in Norway followed quite different lines than that of the American car (Østby, 1995). This object-centeredness might again be a fruitful entrance to the question of empirical studies. In the following section, we give a brief overview of some of the types of empirical research that have been undertaken in a
Nordic STS setting. Could it be that the types of large institutions that are prevalent in the Nordic countries play a distinct role in the types of topics that have been and continue to be discussed within Nordic STS? That the welfare state does not just provide the type of state-sponsored support which makes so many outside the Nordic countries somewhat skeptical, but also provides STS scholars with a wealth of interesting subject matter for further study?

One example can be drawn from the debate at Hell, where Kristin Asdal used the term 'science-state nexus' when pointing to an important difference between STS in a Nordic context and the U.S. Where much American STS-research has centered on the interface between science and industry, much Nordic STSresearch centers on the crossroad between science and the state. ${ }^{2}$ The Nordic welfare states are highly involved in the shaping of both scientific research and technological development, and the involvement seem to take different shapes as they both initiate, fund, shape and respond to much of the research being conducted. There are however significant differences between the Nordic countries. Whereas Sweden has large industrial funds going into research, the private funds available to researchers in Norway are microscopic compared to state funds (Skoie, 2005). In addition, there was a significant build-up of state ownership in Norwegian industry after WWII, a trend that seemed to strengthen as Norway struck oil (Sejersted, 2005).

This acknowledgement of the importance of contextualizing our objects of study and the contexts they change prompts a further question: Are there local flavors to STS-research in the various centers and departments in the Nordic countries? In order to give a brief sample of research going on in the Nordic countries, and given that Nordic STS research is highly institutionalized, it is reasonable to use some of the dedicated institutions as a point of departure. ${ }^{3}$

\section{Nordic institutions}

Starting with Sweden, we see that according to Aant Elzinga, Swedish STS grew out of a discussion about research policy in the 1960 s and that centers investigating questions related to science, technology and society was established in the 1970s. He identifies Lund and Gothenburg as universities that had significant groups. However, writing in the 1980s, Elzinga concluded that in Sweden, policymakers and bureaucrats showed little interest in the field (Elzinga, 1980). Since Elzinga wrote his article in 1980, this seems to have changed, and the Swedish STS-community has grown considerably. The Center for Science and Technology Studies in Uppsala has become a hub for associates from a range

of departments and disciplines and focus on two broad research programs: Science, technology and business, and science, technology and research policy, respectively. Several of the projects focus on the sectorialisation of research and the role of the university in the new innovation economy. At Sweden's Royal Institute of Technology's Department of History and Philosophy of Technology, the research is more focused on technology and infrastructures. Thematically the research includes energy systems, technological systems and European integration, ICTs, and the infrastructures of arctic knowledge. ${ }^{5}$ At the University of Linköping, the Department of Thematic Studies contains the research unit for technology and 
social change. The research at the unit focuses on energy infrastructures, as well as environmental and medical STS and everyday life in past and present societies. ${ }^{6}$

The Danish organization of the STS-field is somewhat different from the Swedish. First of all, the Danes have established a national association for science and technology studies. In keeping with the science-state nexus, the Danish association for science and technology studies (DASTS) grew out of a research council initiated network for the history and philosophy of science that was established in 1994. DASTS was established to stimulate quality, breadth and cooperation within the STS-community in Denmark and to promote Danish STS in the national and international community. DASTS has about 400 members from a range of disciplines and academic institutions and tie these together with the help of a mailing list, the electronic newsletter "Hugin and Munin" and the journal Encounters.7 That STS in Denmark is institutionalized through a national association may signal that in Denmark there are rather few dedicated STS departments or centers. The Center for Medical Science and Technology Studies and the Center for Science, Technology and Society at Aarhus University are two examples of the opposite. Still, many Danish STS-groups seem to be situated within thematically oriented research groups, centers or departments rather than field demarcated institutions. This makes the STS-scene quite diverse, but at the only dedicated centers medical STS is prevalent. Other important research themes for the Danish community are sustainable transitions, media and innovation. ${ }^{8}$ Compared to the Swedish case, historical STS seems to have a weaker standing than anthropological and sociological perspectives in Denmark, which is illustrated by the newly established research group "Technoanthropology" at Aalborg University. ${ }^{9}$

Finland is the other Nordic country where a national organization exists to gather all the animals of the STS-forest. The Society for Science and Technology Studies was established in 1985 and gathers just over one hundred members. ${ }^{10}$ Finland is also home to one of the larger STS journals in Europe, Science and Technology Studies, now the official journal of the European Association for the Study of Science and Technology (EASST)." Furthermore, Finland houses the Research Center for Knowledge, Science, Technology and Innovation studies at the University of Tampere. This center does research ranging from the politics of knowledge, institutions and research community, via technology and everyday life and to the study of innovation systems..$^{12}$ As in the other Nordic countries, there are significant STS groups situated in other institutions than the dedicated STS-centers, and many of the groups are very active in educating PhD-students and conducting research. ${ }^{13}$ Also, the University of Helsinki and Aalto University has established the network unit Helsinki Institute of Science and Technology Studies (HIST). This institute is to strengthen the research and education and the institutional basis for Finnish STS. Research at this institute includes research on green economies, innovation, risk governance, nanotechnologies and climate policy. ${ }^{14}$

The Center for Technology, Innovation and Culture (TIK) is one of three established Norwegian STS research centers. As the other STS-institutions in Norway, this center was established in the 1980 s in the aftermath of discussions about the social consequences of new science and technology. TIK has two main foci of research: Innovation studies and science, technology and culture. Whereas the first group is oriented towards the study of innovation systems, the latter approaches science and technology with a focus on policy and politics. Of research topics, we can mention that TIK-researchers are investigating the politics of nature, risk, expertise and consumption. ${ }^{15}$ The sibling STS-institution of TIK, is the Center for Technology and Society (CTS) located at the Department of Interdisciplinary Studies of Culture in Trondheim. Here, the focus of research tends to be on STS related to ICTS, energy and climate change, biopolitics and consumption..$^{16}$ In addition, TIK and CTS cooperate through the Center for Sustainable Energy Studies. ${ }^{17}$ In Bergen, you find the Center for the Study of the Sciences and Humanities (CSSH). They focus on philosophy and theory of science and research topics include ethics of science and technology, uncertainty and risk as well as the evaluation of the social impact of science and technology. ${ }^{18}$

So far, Iceland does not have an established STS institution in itself, but there are clusters of related work being done, for example in the Center for Equality, Diversity, Development and Advancement $(E D D A)^{19}$ at the University of Iceland, which does work on questions of sustainability, citizenship and transition theories among others.

\section{A place of one's own}

So far a quick look at STS institutions in the Nordic countries. What can we make of this? First of all, it's clear that many of the scholars identifying as working within STS are not situated at dedicated STS-departments or centers. Some are located at disciplinary units such as departments for sociology, history, anthropology, while others are working in what is termed the institute sector. However, this is more or less the modus operandi for STS all over the world. As stated in the introduction of this article, Nordic STS does enjoy a high degree of institutionalization and the various institutions do have






a different flavor of STS-research. This is perhaps best illustrated by the strong position enjoyed by historical STS in Sweden and the strong position of anthropology in Danish STS. Also, Norwegian STS communities can be said to have an interest in the integration of science and technology in common, while the Swedes seems to be more geared towards infrastructures and institutions. This might have historical reasons that involve the shape of the R\&D-systems in Norway and Sweden, but also the structures of economic life: Where Norwegian economic life centers on raw materials and have imported most of its technologies outside the specific petroleum related ones, the Swedes have a strong industrial-innovation legacy.

In line with Jasanoff's injunction to act as explorers between and within fields, we have tried here to give a very rough sketch of what STS in the Nordic countries might entail. Of course, providing a more detailed picture will require more extensive work and space than available here, as the STS-jungle in the Nordic countries has grown so wild that mapping it completely would be almost impossible.20 However, the ways in which Nordic STS researchers have pursued research into the "science-state" nexus might give us some insight into the questions posed in our initial discussion of the ways a Nordic STS might merit attention. Nordic STS has for the most part relied on using concepts from the general, international STS literature, even though exceptions exist, for example the work done on domestication theory (Williams \& Sørensen, 2002). Still, the process of translation and domestication has resulted in a highly diverse field, which speaks to the general usability and malleability of theory. In light of this, we have tried to show how STS in the Nordic countries both carries on work within a clear tradition, and gives that tradition as it is expressed in those countries a flavor of its own.

A way to talk about this flavor might have been through the concept of cultural de- and re-territorialisation, which posits a relation between culture ${ }^{21}$ and geographical and social territory (Canclini, 1995). Could the same hold for theory? One problem is that deterritorialisation mostly applies to situations of the margin. While it is true that the Nordic region is not the most central in the world, it would be disingenuous to make use of the language of marginalization from a position which is so clearly privileged as that of scholars in some of the richest countries in the world. There is, however, a perfectly usable Norwegian word for what we are trying to convey, which should be legible for at least Swedes and Danes as well: Stedegenhet - literally, "place-ownness". Stedegenhet points to the way a place-specific setting might influence the way a question is asked or an investigation undertaken, all the while avoiding the somewhat uncomfortable connotations of a concept like terroir, which carries with it a sense of essentialism. Stedegenhet also has the fortuitous feature of having a double meaning - egen meaning both "own" and "stubborn" - correlating to the partly independent and outsider status of Europe's northern extremes.22 When considering that every place, sted, is in constant development, it should be obvious that it's not clear what Nordic STS is. What we need is a constant discussion of what it might become over and over again.

\section{Conclusion}

As stated initially, one impetus for this text is a slight unease with the way STS theory is often presumed to be global, with universal concepts applicable to all sorts of different contexts. The question is: how should we deal with this unease? Our asking this question might make it seem that we think STS is in some sort of crisis. This is not our position at all (indeed, if this was the case, why launch an STS journal in the first place?). To the contrary, we believe that it is precisely because STS is doing so well both theoretically and institutionally that it is time to ask these types of questions. We see in STS the potential for a cosmopolitical type of theory, ${ }^{23}$ one that disseminates across borders, languages and epistemic cultures and simultaneously morphs and incorporates local impulses. The analogy of a rhizome might seem a tired one, but if there is one type of thinking that has the ability to move and grow rhizomatically, it has to be STS, a point already made in a discussion of Norwegian STS (Sørensen, 2012). Drawing on this, we see many possibilities for Nordic STS to spread out in the future, while still exhibiting some of that strange stedegenhet which ensures that just this work will not be done anywhere else in the world, at least

not in exactly the same way and form. We also believe that the examples we provided earlier of how STS research has been conducted in the Nordic countries demonstrate that this potential always has been present in the discipline. This can be nothing but a strength. After all, why is science and technology studies oriented research coupled with gender studies in Trondheim yet located in a business school in Copenhagen? Why do STS scholars combine so well with history in Sweden but move in the field of innovation studies in Finland? Don't these examples demonstrate that STS is uniquely capable of handling the interdisciplinary challenges of modern social research? We think so, and welcome the opportunity to contribute to the continued messy growth of the roots and shoots that stem from what Donna Haraway has called the 'fertile compost pile' of science and technology studies. 
Henrik Karlstrøm (PhD) is editor of Nordic Journal of Science and Technology Studies and researcher at the Department of Interdisciplinary Studies of Culture, NTNU. His research focuses on issues of sustainable energy and the public engagement with new energy technologies.

Terje Finstad $(\mathrm{PhD})$ is a researcher at the Department of Interdisciplinary Studies of Culture, NTNU. His research centers on historical science and technology studies. He is currently working on a project about the relations between science, technology, safety and trust in industrialized food systems.

\section{References}

Andersen, T. M., Holmström, B., Honkapohja, S., Korkman, S., Tson, S. H., and Vartiainen, J. 2007. The Nordic Model. Embracing globalization and sharing risks. ETLA B.

Callon, M. 1986. Some elements of a sociology of translation: domestication of the scallops and the fishermen of St Brieuc Bay. In J. Law (ed.), Power, action and belief: a new sociology of knowledge? 196-223.

Canclini, N. G. 1995. Hybrid cultures, oblique powers. In Hybrid Cultures: Strategies for Entering and Leaving Modernity. 207-263.

Christiansen, N. 2006. The Nordic model of welfare: a historical reappraisal. Museum Tusculanum Press.

Collins, H., and Evans, R. 2008. Rethinking expertise. University of Chicago Press.

Creager, A., Grandin, K., Wormbs, N., and Widmalm, S. 2004. The science-industry nexus: History, policy, implications.

Dear, P., and Jasanoff, S. 2010. Dismantling boundaries in science and technology studies. Isis; an international review devoted to the history of science and its cultural influences, 101(4), 759-74.

Elzinga, A. 1980. "Science Studies" in Sweden. Social Studies of Science, 10(2), 181-214.

Etzkowitz, H., and Leydesdorff, L. 2000. The dynamics of innovation: from National Systems and "Mode 2" to a Triple Helix of university-industry-government relations. Research policy, 29(2), $109-123$.

Jantti, M., Bratsberg, B., Røed, K., Raaum, O., Naylor, R., Osterbacka and E., Eriksson, T. 2006. American exceptionalism in a new light: a comparison of intergenerational earnings mobility in the Nordic countries, the United Kingdom and the United States. IZA Discussion Paper.

Jasanoff, S. 1995. Science at the bar: law, science, and technology in America. Cambridge, Mass.: Harvard University Press.

\section{Acknowledgements}

Both authors are funded by the Norwegian Research Council. We are grateful to our two reviewers for useful comments.

Jasanoff, S. (ed.). 2004. States of knowledge: the co-production of science and social order. London: Routledge.

Knorr-Cetina, K. 2007. Culture in global knowledge societies: Knowledge cultures and epistemic cultures. Interdisciplinary Science Reviews, 32(4), 361-375.

Latour, B. 1983. Give me a laboratory and I will raise the world. In K. Knorr-Cetina \& M. J. Mulkay (eds.), Science observed: Perspectives on the social study of science. 141-170.

Latour, B. 2010. The making of law: an ethnography of the Conseil d'État. Polity.

Law, J. 2008. On sociology and STS. The Sociological Review, 56 (4):623-649.

Sejersted, F. 2005. Sosialdemokratiets tidsalder. Pax Oslo.

Skoie, H., 2005. Norsk forskningspolitikk i etterkrigstiden. Cappelen Akademisk.

Stengers, I., and Bononno, R. 2011. Cosmopolitics II. University of Minnesota Press.

Sørensen, K. H. 2012. Disciplined Interdisciplinarity? A Brief Account of STS in Norway. Tecnoscienza, 3(1), 49-61.

Williams, R., and Sørensen, K. H. 2002. Shaping technology, guiding policy: concepts, spaces and tools. Cheltenham: Edward Elgar.

Wynne, B. 2007. Dazzled by the mirage of influence? STS-SSK in multivalent registers of relevance. Science, Technology \& Human Values, 32(4), 491-503.

Østby, P. 1995. Flukten fra Detroit: bilens integrasjon i det norske samfunnet. Universitetet i Trondheim. Senter for teknologi og samfunn. 